\title{
BMJ Open Single-centre, double-blind, randomised, parallel-group, superiority study to evaluate the effectiveness of general anaesthesia and ultrasound-guided transversus thoracis muscle plane block combination in adult cardiac surgery for reducing the surgical stress response: clinical trial protocol
}

\author{
A A Gde Putra Semara Jaya (D , ${ }^{1}$ Aida Rosita Tantri, ${ }^{1}$ Aldy Heriwardito, ${ }^{1}$ \\ Arif Mansjoer $^{2}$
}

To cite: Jaya AAGPS, Tantri AR, Heriwardito A, et al. Single-centre, doubleblind, randomised, parallelgroup, superiority study to evaluate the effectiveness of general anaesthesia and ultrasound-guided transversus thoracis muscle plane block combination in adult cardiac surgery for reducing the surgical stress response: clinical trial protocol. BMJ Open 2021;11:e051008. doi:10.1136/ bmjopen-2021-051008

- Prepublication history and additional supplemental material for this paper are available online. To view these files, please visit the journal online (http://dx.doi.org/10.1136/ bmjopen-2021-051008)

Received 09 March 2021 Accepted 25 October 2021

Check for updates

(C) Author(s) (or their employer(s)) 2021. Re-use permitted under CC BY-NC. No commercial re-use. See rights and permissions. Published by BMJ.

For numbered affiliations see end of article.

Correspondence to Dr Aida Rosita Tantri; aidatantri@yahoo.com

\section{ABSTRACT}

Introduction Adult open-heart surgery is a major surgery that causes surgical stress response and activation of the immune system, contributing further to postoperative complications. Transversus thoracis muscle plane block (TTPB) may potentially benefit in reducing the surgical stress response. This study aims to know the effectiveness of preoperative TTPB in adult open-heart surgery for reducing the surgical stress response.

Methods and analysis This study is a prospective, double-blind, randomised control trial comparing the combination of general anaesthesia and TTPB versus general anaesthesia only in adult open-heart surgery. Forty-two eligible subjects will be randomly assigned to the TTPB group or control group. The primary outcomes are the difference between the two groups in the means of postoperative cortisol and interleukin- 6 plasma levels at 24 hours and 48 hours after cardiac intensive care unit admission. The secondary outcomes are the difference between the two groups in the means of total 24-hour postoperative morphine consumption and time of first postoperative patient-controlled analgesia (PCA) dose. Ethics and dissemination The study protocol and informed consent forms have been reviewed and approved by the Ethics Committee of Faculty of Medicine Universitas Indonesia/Dr. Cipto Mangunkusumo Hospital. The result will be released to the medical community through presentation and publication in peer-reviewed journals. Trial registration number NCT04544254.

\section{INTRODUCTION}

Background and rationale

Adult open-heart surgery is associated with stress response due to surgical trauma, cardiopulmonary bypass (CPB), blood

\section{Strengths and limitations of this study}

The study is a double-blind, randomised and controlled trial.

- Addition of preoperative adductor canal block when great saphenous vein harvesting is required.

- The study is carried out at a tertiary academic and national referral hospital.

- Subjects are patients with a specific bodyweight range to achieve an equal range of local anaesthetic doses.

- Postoperative patient-controlled analgesia is limited only to the first 24 hours.

transfusion and hypothermia. ${ }^{1-3}$ These conditions trigger immune system activation. Exaggerated immune system activation is correlated with severe postoperative complications. ${ }^{4}{ }^{5}$ Regional anaesthesia has been known can minimise the surgical injuryrelated stress response. ${ }^{1-36}$

The surgical injury-related stress response involves hormonal and metabolic changes, with systemic neuroendocrine and haematoimmunological systems involvement. The neuroendocrine and haemato-immunological systems interact bidirectionally. Initially, major surgical trauma causes significant local inflammation, then induces the systemic inflammation reaction, followed by increasing acute phase proteins, activation of proinflammation mediators and lead to activation of hypothalamus-pituitary-adrenal 
axis and sympathetic nervous system through the neural and humoral pathway. Immune systems also activate the anti-inflammation response, which would modulate the proinflammatory phase, restoring homoeostasis. ${ }^{7-11}$

In the majority of cases, the first 36 hours after trauma is dominated by activation of proinflammatory, followed with moderate immune suppression for the next few days. ${ }^{312}$ Interleukin (IL)-6 is the essential proinflammatory cytokine associated with surgical trauma and the main cytokine responsible for inducing the acute phase response. ${ }^{13-15}$ IL-6 peak circulating levels are found at about 12-24hours after surgery and remain elevated for $48-72$ hours postoperatively. ${ }^{714}$ Several studies and metanalysis suggest that surgical trauma, rather than $\mathrm{CPB}$, initiates the secretion of IL-6. ${ }^{1016} 17$ Cortisol are prominent markers of hormonal response to surgery. Cortisol is a stress hormone with immunosuppression activity. ${ }^{8}{ }^{12}$ Immediately after the surgery, cortisol decreases and followed by an increase at about 24 hours postoperatively. ${ }^{610}$

The addition of regional anaesthesia has the potential benefit in reducing the risk of stress response after open-heart surgery. The mechanism of local anaesthetics in minimising stress response through inhibition of nociceptive transmission from injured tissues to central nervous system, decrease neurogenic inflammation and systemic anti-inflammatory effect of local anaesthetics. ${ }^{5-71418}$ Thoracic epidural has been shown to have benefits, ${ }^{6}{ }^{19}$ however, most anaesthesiologists are worried about performing it due to the risk of neurological complications.

Inflammation and pain are related to one another and associated with tissue damage. Postoperative pain is most intense during the first 24 hours and sternotomy is frequently reported as the most painful area after cardiac surgery. ${ }^{20-23}$ Transversus thoracis muscle plane block (TTPB) is an ultrasound (US)-guided anterior chest wall fascial plane block. It blocks multiple anterior branches of intercostal nerves (Th2-6) which innervate the sternum area. ${ }^{24}$ US guidance increases the safety profile of TTPB by real-time visualisation of needle tip, evaluation of adjacent vital structure and distribution of local anaesthetics. ${ }^{25}$ A pilot study of TTPB for cardiac surgery, ${ }^{26}$ a study of TTPB on postoperative opioid consumption, ${ }^{27}$ and a study of the superficial parasternal interfascial plane block on postoperative inflammatory response ${ }^{28}$ had been reported. However, to our knowledge, no study evaluates the effectiveness of preoperative TTPB in adult cardiac surgery for reducing the surgical stress response.

\section{Objectives}

This study's primary objective is to determine whether the combination of general anaesthesia and US-guided TTPB is superior to general anaesthesia only in reducing the postoperative open-heart surgery stress response (measured by comparison of the means of postoperative cortisol and IL-6 plasma levels at 24 hours and 48 hours). The secondary objective is to determine whether the combination of general anaesthesia and US-guided TTPB is superior to general anaesthesia only in reducing total 24-hour morphine consumption and time of first postoperative patient-controlled analgesia (PCA) dose.

\section{Trial design}

This is a single-centre, double-blind, randomised, controlled, superiority study with two parallel groups to evaluate cortisol and IL-6 plasma levels during perioperative period. Randomisation will be performed using permuted block randomisation, participants will be randomly assigned to either TTPB or control group with a 1:1 allocation.

\section{METHODS AND ANALYSIS}

We used the Standard Protocol Items: Recommendations for Interventional Trials checklist when writing our report. $^{29}$

\section{Participants, interventions and outcomes}

\section{Study setting}

This is a single-centre study at Dr. Cipto Mangunkusumo Hospital, the Joint Commission International-accredited tertiary academic hospital in Indonesia. Located in Jakarta, the capital city of Indonesia, Dr. Cipto Mangunkusumo Hospital is the national central public hospital of the Ministry of Health Republic of Indonesia.

\section{Inclusion criteria}

1. Adult patients aged $19-75$ years old.

2. Will undergo elective open-heart surgery with median sternotomy approach.

\section{Exclusion criteria}

1. Patients who refuse to participate in this study.

2. Body weight $<45 \mathrm{~kg}$ or $>75 \mathrm{~kg}$.

3. Patients with chronic obstructive pulmonary disease.

4. Patients with chronic kidney disease who needs regular haemodialysis.

5. Patients with local infection in the injection area for TTPB.

6. Patients with chronic pain.

7. Patients with long-term usage of analgesics.

8. Patients who are contraindicated for local anaesthetics.

9. Patients with communication disability.

10. Patients with cognitive disorders.

11. Patients with severe psychiatric disorders, such as schizophrenia and bipolar disorder.

\section{Drop-out criteria}

1. Participants died during the data collection period.

2. Aortic cross-clamp time $>120 \mathrm{~min}$.

3. Participants who have delayed sternal closure.

4. Participants who underwent resurgery during the treatment period.

5. Participant decided to leave the study. 


\section{Interventions}

All participants will receive general anaesthesia. Induction of anaesthesia will be obtained using midazolam $0.05-0.1 \mathrm{mg} / \mathrm{kg}$ intravenous, fentanyl 2-4 $\mu \mathrm{g} / \mathrm{kg}$ intravenous and sevoflurane 2 vol $\%$ with $100 \%$ oxygen. Rocuronium $0.6-1.2 \mathrm{mg} / \mathrm{kg}$ intravenous will be used to facilitate tracheal intubation. General anaesthesia will be maintained using sevoflurane and oxygen mixed with compressed air, morphine $5 \mu \mathrm{g} / \mathrm{kg} / \mathrm{hour}$ intravenous and rocuronium $0.1-0.2$ intravenous $\mathrm{mg} / \mathrm{kg}$ every 30-45 min. Fentanyl $1 \mu \mathrm{g} / \mathrm{kg}$ intravenous will be administered 2-3 min before skin incision. Intermittent fentanyl intravenous will be given as intraoperative rescue analgesia by the discretion of the cardiovascular anaesthesiologist consultant.

Participants in the TTPB group will receive TTPB after induction of general anaesthesia by a single investigator (AAGPSJ) who has experience in performing TTPB. A high-frequency linear US transducer (HFL38×, 13-6 MHz, Sonosite M-Turbo, Fujifilm) will be placed sagitally, lateral to sternal edge, at fourth intercostal space. A lateralmedial scanning will then be performed to visualise the structures: transversus thoracis muscle (TTM), internal intercostal muscle (IIM) and pectoralis major muscle. Colour Doppler will be used to confirm the internal thoracic artery. A 22G, $50 \mathrm{~mm}, 30^{\circ}$ bevel needle (Stimuplex Ultra 360, B. Braun Medical Inc.) will be inserted in-plane to US probe from caudal to cranial. Real-time needle tip movement will be observed using US to avoid arterial and pleural puncture. When the plane between TTM and IIM has been reached, hydro dissection using 1-2 $\mathrm{mL}$ saline will be obtained to confirm the correct needle tip placement and followed by incremental injection of $20 \mathrm{~mL}, 0.25 \%-0.375 \%$ bupivacaine. The same procedure will then be repeated on the contralateral side. AAGPSJ will prepare local anaesthetics before the intervention. A total of $2 \mathrm{mg} / \mathrm{kg}$ of bupivacaine hydrochloride $0.5 \%$ will be diluted with saline to achieve a $40 \mathrm{~mL}$ solution for bilateral TTPB. Participants in the control group will receive bilateral superficial needle puncture at a location like TTPB without any solution injected.

Patients who will undergo open harvesting of great saphenous vein for coronary artery bypass grafting will also receive adductor canal block. A total of $5 \mathrm{~mL}, 0.25 \%$ bupivacaine will be placed anterolateral to femoral artery, deep to sartorius muscle, under US guidance. The same needle for TTPB will be used using either an in-plane or out-of-plane approach. A contralateral adductor canal block will be performed if a bilateral great saphenous vein graft is planned.

In the postoperative period, all participants will receive patient-controlled intravenous analgesia (PCIA) (Perfusor PCA Syringe Pump, B. Braun Medical) morphine, in combination with paracetamol intravenous $1 \mathrm{~g}$ every 8 hours. The PCIA will be set as follow: $1 \mathrm{mg} /$ $\mathrm{mL}$ of morphine, background infusion $5 \mu \mathrm{g} / \mathrm{kg} / \mathrm{hour}$, PCA dose $1 \mathrm{mg}$, lockout interval $10 \mathrm{~min}$, maximum dose $10 \mathrm{mg} / 4$ hours. In the early postoperative period, when the patient is not yet awake and able to report pain, an anaesthesiology resident on duty will give PCA demand dose if pain score $>2$ using the Critical Care Pain Observation Tool (CPOT). CPOT consists of four domains: facial expression, body movements, muscle tension and compliance with ventilation. Every behavioural domain has three scores: 0,1 and 2, then the total score ranges between 0 and 8 .

\section{Primary outcome}

Difference between the two groups in the means of postoperative cortisol and IL-6 plasma levels at 24 hours and 48 hours after cardiac intensive care unit (CICU) admission.

\section{Secondary outcomes}

1. Difference between the two groups in the means of total 24-hour postoperative morphine consumption.

2. Difference between the two groups in the means of time of first postoperative PCA dose.

\section{Participant timeline}

The schedule of participants' enrolment, interventions and assessments are presented in table 1 .

\section{Sample size}

In agreement with previous studies by Loick $e t a t^{6}$ and $\mathrm{Xu}$ et $a l,{ }^{30}$ the expected SD of cortisol and IL-6 plasma levels were $11 \mu \mathrm{g} / \mathrm{dL}$ and $7 \mathrm{pg} / \mathrm{mL}$, respectively. The sample size was calculated using the formula for comparing two independent means to achieve a power of $80 \%$ and a level of significance of $5 \%$ (two sided). Based on cortisol plasma level, with the determined difference in the two means $10 \mu \mathrm{g} / \mathrm{dL}$, the study would require a sample size of 18 for each group. Based on IL-6 plasma level, with the determined difference in the two means $8 \mathrm{pg} / \mathrm{mL}$, the study would require a sample size of 12 for each group. We will include 18 participants in each group. A total of 42 participants will be enrolled in this study, with equal allocation to two arms and given a drop-out of $10 \%$.

\section{Recruitment}

Adult patients who will undergo elective open-heart surgery will be recruited in the ward 1-2 days before the procedure by AAGPSJ. The surgical schedule will be obtained every day from the hospital information system. Patient will be introduced to this study by slide with pictures and important trial points using a tablet computer. We estimate that the recruitment will take at least 8 months. Participants will not receive any financial or non-financial incentives.

\section{Assignment of interventions}

Participants will be randomly assigned to either TTPB or control group with a 1:1 allocation using permuted block randomisation. We will determine the block size and use the random number table for sequence generation. Random allocation sequence will be generated by an assistant who is not involved in this study. He/she will 
Table 1 Schedule of enrolment, interventions and assessments

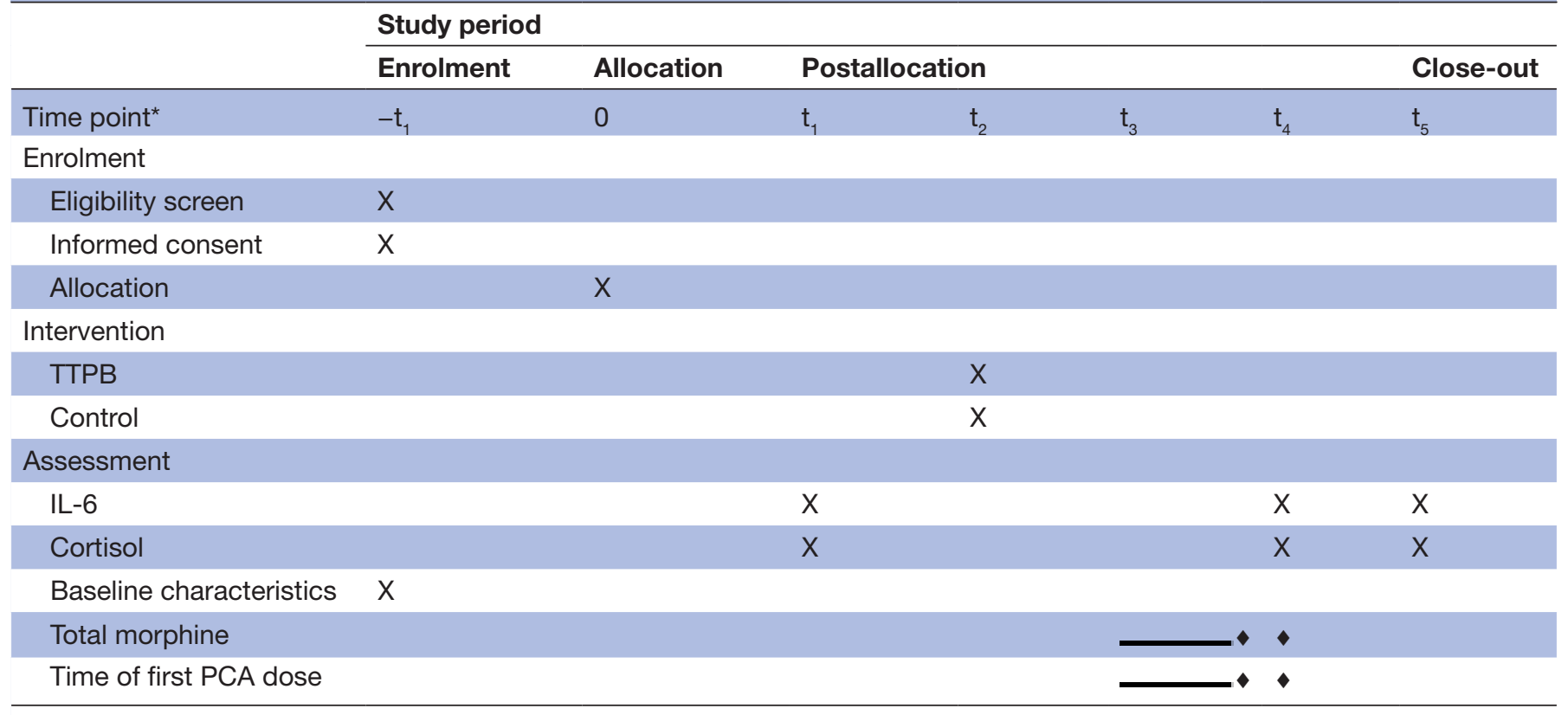

${ }^{*}-t_{1}$ : preoperative, $t_{1}$ : before induction of general anaesthesia, $t_{2}$ : after induction of general anaesthesia, $t_{3}:$ CICU admission, $t_{4}: 24$ hours postoperative, $\mathrm{t}_{5}: 48$ hours postoperative.

CICU, cardiac intensive care unit; IL-6, interleukin-6; PCA, patient-controlled analgesia; TTPB, transversus thoracis muscle plane block.

conceal the allocation sequence using opaque envelopes with instructions on preparing the drug for injections. Allocation concealment is also ensured by not open the envelopes until all baseline measurements have been recorded, and we will not disclose the block sizes.

AAGPSJ will be responsible for subjects' enrollment and assign patients to intervention. Study participants, care providers and outcome assessors will be blinded to treatment allocation. AAGPSJ will prepare the drugs and perform the intervention, but not get involved in anaesthesia management and outcome assessment. Medical staff who manage anaesthesia and measure the outcomes will come out of the operating room. Subjects in the control group will receive superficial needle puncture without administration of saline to maintain the blinding. The duration of intervention in the control group is also equalised as in the TTPB group.

\section{Data collection, management and analysis \\ Primary outcome}

Cortisol and IL-6 plasma levels will be measured using the ELISA method at Integrated Laboratory of Faculty of Medicine Universitas Indonesia. An amount of $3 \mathrm{~mL}$ of vein blood sample will be withdrawn from central venous catheter. It will be collected to EDTA tube passively. The evaluation will be performed three times: before intervention, at 24 hours and 48 hours after CICU admission. Unit for cortisol and IL-6 are $\mu \mathrm{g} / \mathrm{dL}$ and $\mathrm{pg} / \mathrm{mL}$, respectively.

\section{Secondary outcomes}

1. Total 24-hour postoperative morphine consumption will be collected from PCA machine recording by anaesthesiology resident on duty. Starting from CICU admission time, include 24-hour background infusion dose and administered PCA dose. Unit: milligrams (mg).

2. Time of first postoperative PCA dose will be collected from CICU chart by anaesthesiology resident on duty. Calculated from the end of intervention time. Unit: minutes (min).

\section{Data management and analysis}

All data will be manually recorded in case report forms. Electronic version or soft copy of data will be made after data collection is completed. Original case report forms will be stored in locked file cabinets in our department with limited access. Those files will be in storage for a period of 3 years after completion of the study.

We will use Stata Statistical Software: Release V.15 (StataCorp) for all statistical analyses. Participants' baseline characteristics will be analysed descriptively. Numerical variables will be presented as mean $\pm \mathrm{SD}$ or median (IQR), while categorical variables will be presented as frequency distribution. Before further analyses, we will perform testing for normality and homogeneity. Data will be considered normally distributed and homogeneity of variance if $p>0.05$ by Shapiro-Wilk test and Levene's test, respectively. Difference between the two groups in the means of postoperative cortisol and IL-6 plasma levels at 24 hours and 48 hours after CICU admission will be analysed using general linear model-repeated measures. Difference between the two groups in the means of total 24-hour postoperative morphine consumption and time of first postoperative PCA dose will be analysed using independent t-test or Mann-Whitney test. We use twosided $\mathrm{p}$ values with significance level of $5 \%$ for all tests. 
Table 2 Trial registration data

\begin{tabular}{ll}
\hline Data category & Information \\
\hline Primary registry and trial identifying & ClinicalTrials.gov NCT04544254 \\
no
\end{tabular}

Date of registration in primary $\quad 10$ September 2020

registry

\begin{tabular}{|c|c|}
\hline Secondary identifying numbers & $\mathrm{N} / \mathrm{A}$ \\
\hline $\begin{array}{l}\text { Source(s) of monetary or material } \\
\text { support }\end{array}$ & Universitas Indonesia \\
\hline
\end{tabular}

support

\begin{tabular}{ll} 
Primary sponsor & Universitas Indonesia \\
\hline Secondary sponsor(s) & None \\
\hline $\begin{array}{l}\text { Contact for public queries } \\
\text { Contact for scientific queries }\end{array}$ & $\begin{array}{l}\text { A A Gde Putra Semara Jaya, MD (gungthey84@yahoo.com) } \\
\text { Intensive Care, Dr. Cipto Mangunkusumo Hospital - Faculty of Medicine Universitas Indonesia. }\end{array}$ \\
\hline Public title & Effectiveness of transversus thoracis muscle plane block in adult cardiac surgery. \\
\hline Scientific title & $\begin{array}{l}\text { Effectiveness of general anaesthesia and ultrasound-guided transversus thoracis muscle } \\
\text { plane block combination in adult cardiac surgery for reducing the surgical stress response: a } \\
\text { randomised, double-blind, controlled trial. }\end{array}$ \\
\hline Countries of recruitment & Indonesia
\end{tabular}

Health condition(s) or problem(s) Adult cardiac surgery, stress response (interleukin-6, cortisol).

studied

$\begin{array}{ll}\text { Intervention(s) } & \text { Active comparator: transversus thoracis muscle plane block. } \\ \text { Placebo comparator: superficial needle puncture without administration of drugs (matching }\end{array}$ location and duration of procedures).

Key inclusion and exclusion criteria Inclusion criteria: adult patients aged 19-75 years old, will undergo elective open-heart surgery with median sternotomy approach.

Exclusion criteria: refuse to participate in this study, body weight $<45 \mathrm{~kg}$ or $>75 \mathrm{~kg}$, chronic obstructive pulmonary disease, chronic kidney disease who needs regular haemodialysis, local infection in the injection area, chronic pain, long-term usage of analgesics, contraindicated for local anaesthetics, communication disability, cognitive disorders, severe psychiatric disorders.

\begin{tabular}{ll} 
Study type & $\begin{array}{l}\text { Interventional } \\
\text { Allocation: randomised; Intervention model: parallel; masking: double-blind. } \\
\text { Purpose: effectiveness of transversus thoracis muscle plane block for reducing the surgical } \\
\text { stress response. }\end{array}$ \\
\hline Date of first enrolment & 28 September 2020 \\
\hline Target sample size & 42 \\
\hline Recruitment status & Recruiting \\
\hline Primary outcome(s) & $\begin{array}{l}\text { Difference between the two groups in the means of postoperative cortisol and IL-6 plasma levels } \\
\text { at } 24 \text { hours and } 48 \text { hours after cardiac intensive care unit admission. }\end{array}$ \\
\hline Key secondary outcomes & Difference between the two groups in the means of total 24-hour postoperative morphine \\
& consumption and time of first postoperative PCA dose.
\end{tabular}

IL-6, interleukin 6; N/A, not available; PCA, patient-controlled analgesia.

All analyses will be conducted by AM who is blinded to trial groups.

\section{Monitoring}

Adverse events will be collected and recorded only after the participants receive appropriate treatment and intervention until CICU discharge. The Good Clinical Practice Guidelines of the International Council for Harmonisation of Technical Requirements for Pharmaceuticals for Human Use (ICH-GCP) defined adverse events as any untoward medical occurrence in a study participant and that does not necessarily have a causal relationship with the treatment/intervention.

Serious adverse events (SAE) between enrollment and CICU discharge will be reported within 24 hours to the ethics committee and the quality, safety and performance committee. Any adverse event which poses a threat to the patient's life or functioning or meet at least one of SAE criteria: death or lifethreatening (immediate risk of death), or requires hospitalisation or prolongs an existing hospitalisation, or causes persistent or significant disability, or 
requires medical intervention to prevent one of the above outcomes.

The local anaesthetic systemic toxicity (LAST), pneumothorax, haematoma and local site infection will be monitored intraoperatively and postoperatively after the intervention. Physical examination, US, and/or X-ray will be used to assess the adverse events. The LAST will be prevented by using US-guided technique, aspiration before local anaesthetics injection, and incremental administration of local anaesthetics. Pneumothorax and haematoma will be prevented by using US-guided technique. We will use aseptic technique practice when performing the procedure to prevent pathogens contamination.

\section{Patient and public involvement}

Patients or members of the public were not involved in the design, and will not be involved in the conduct, or reporting, or dissemination plans of our research.

\section{ETHICS AND DISSEMINATION}

\section{Ethical approval and amendment}

The study protocol and informed consent forms have been reviewed and approved by Ethics Committee of Faculty of Medicine Universitas Indonesia/Dr. Cipto Mangunkusumo Hospital with regards to the protection of human rights and welfare in medical research, under the ICH-GCP standard procedures (protocol number 19-11-1282, ethical approval number KET-539/ UN2.F1/ETIK/PPM.00.02/2020 on 3 June 2020). This research has also been approved by the Innovation and Intellectual Property Management Installation of Dr. Cipto Mangunkusumo Hospital (approval number LB.02/2.6.1/0082/2020 on 14 September 2020).

Any modification in the protocol, informed consent forms, participant education and other requested documents also will be reviewed and approved by the Ethics Committee. This study's protocol amendment has been submitted before participant recruitment regarding inclusion and drop-out criteria, blinding technique and local anaesthetic dose. The Ethics Committee of Faculty of Medicine Universitas Indonesia/ Dr. Cipto Mangunkusumo Hospital reviewed and approved the amendment on 27 July 2020.

The ethical approval is valid for 1 year, beginning from the date of approval. We will make progress and safety reports to the Ethics Committee at least annually. Review and ethical approval renewal submission will be done if required. A final report will be submitted following the completion of the study. This study has already begun. The subjects' recruitment starts on 28 September 2020, and reaches 16 subjects when the manuscript was written.

\section{Consent}

AAGPSJ will perform the introduction to the study, education, and consent for all participants. Images and information sheets in the Indonesian language will be used to introduce the research to patients. The patients can ask questions. Written informed consent will be obtained after discussion and confirmation that the patients understand the study. The model patient consent form is available as an additional file (online supplemental file 1).

\section{Confidentiality}

All data will be stored securely at Department of Anesthesiology and Intensive Care Dr. Cipto Mangunkusumo Hospital - Faculty of Medicine Universitas Indonesia. Documents that contain participants' personal information will be held in locked file cabinets in our research and development division with limited access. We will use coded identification numbers for case report forms, laboratory specimens and other research forms to maintain participant confidentiality. Participant information will also be stored in the hospital information system, a local database secured with a personalised password. The participants' information will only be released outside the trial with participants' written consent, except for monitoring purposes by Ethics Committee, Innovation and Intellectual Property Management Installation, and other regulatory authorities.

\section{Dissemination policy}

The result of this trial will be released to the anaesthesiologist, cardiothoracic surgeon, cardiac intensivist and the medical community through presentation and publication in peer-reviewed journals.

\section{WHO TRIAL REGISTRATION DATA SET}

The summary of this trial registration data set is presented in table 2.

\section{Author affiliations}

${ }^{1}$ Department of Anesthesiology and Intensive Care, Dr. Cipto Mangunkusumo Hospital - Faculty of Medicine Universitas Indonesia, Jakarta Pusat, Indonesia ${ }^{2}$ Division of Cardiology, Department of Internal Medicine, Dr. Cipto Mangunkusumo Hospital - Faculty of Medicine Universitas Indonesia, Jakarta Pusat, Indonesia

\section{Twitter A A Gde Putra Semara Jaya @gungthey84}

Contributors AAGPSJ conceived of the study. All authors initiated the study design and contributed to the refinement of the study protocol. AM and ART provided statistical expertise in clinical trial design. ART and AAGPSJ are grant holders AAGPSJ and AH implement the study. AM will conduct the statistical analysis. All authors contributed to the drafting and revision of the manuscript and approved the final version.

Funding This work was supported by Universitas Indonesia grant number NKB1513/UN2.RST/HKP.05.00/2020.

Disclaimer PT B Braun Medical Indonesia provides PCA machines for postoperative pain management and will not has other involvement in the study.

Map disclaimer The design and conduct of the project, data collection and management, data analysis and result interpretation, and the preparation, review, or approval of the report are entirely independent of the funder.

Competing interests None declared.

Patient consent for publication Not applicable.

Provenance and peer review Not commissioned; externally peer reviewed.

Supplemental material This content has been supplied by the author(s). It has not been vetted by BMJ Publishing Group Limited (BMJ) and may not have been 
peer-reviewed. Any opinions or recommendations discussed are solely those of the author(s) and are not endorsed by BMJ. BMJ disclaims all liability and responsibility arising from any reliance placed on the content. Where the content includes any translated material, BMJ does not warrant the accuracy and reliability of the translations (including but not limited to local regulations, clinical guidelines, terminology, drug names and drug dosages), and is not responsible for any error and/or omissions arising from translation and adaptation or otherwise.

Open access This is an open access article distributed in accordance with the Creative Commons Attribution Non Commercial (CC BY-NC 4.0) license, which permits others to distribute, remix, adapt, build upon this work non-commercially, and license their derivative works on different terms, provided the original work is properly cited, appropriate credit is given, any changes made indicated, and the use is non-commercial. See: http://creativecommons.org/licenses/by-nc/4.0/.

ORCID iD

A A Gde Putra Semara Jaya http://orcid.org/0000-0002-3102-2814

\section{REFERENCES}

1 Asimakopoulos G. Systemic inflammation and cardiac surgery: an update. Perfusion 2001;16:353-60.

2 Laffey JG, Boylan JF, Cheng DCH. The systemic inflammatory response to cardiac surgery: implications for the anesthesiologist. Anesthesiology 2002;97:215-52.

3 Sugita J, Fujiu K. Systemic inflammatory stress response during cardiac surgery. Int Heart J 2018;59:457-9.

4 Shankar Hari M, Summers C. Major surgery and the immune system: from pathophysiology to treatment. Curr Opin Crit Care 2018;24:588-93.

5 Hollmann MW, Durieux ME. Local anesthetics and the inflammatory response: a new therapeutic indication? Anesthesiology 2000;93:858-75.

6 Loick HM, Schmidt C, Van Aken H, et al. High thoracic epidural anesthesia, but not clonidine, attenuates the perioperative stress response via sympatholysis and reduces the release of troponin $\mathrm{T}$ in patients undergoing coronary artery bypass grafting. Anesth Analg 1999;88:701-9.

7 Desborough JP. The stress response to trauma and surgery. $\mathrm{Br} \mathrm{J}$ Anaesth 2000;85:109-17.

8 Gutierrez T, Hornigold R, Pearce A. The systemic response to surgery. Surgery 2011;29:93-6.

9 Ivanovs I, Mihelsons M, Boka V. Stress response to surgery and possible ways of its correction. Proc Latv Acad Sci B: Nat Exact Appl Sci 2012;66:225-33.

10 Saracevic A, Medved I, Hrabric Vlah S, et al. The association of systemic inflammatory markers with indicators of stress and cardiac necrosis in patients undergoing aortic valve replacement and revascularization surgeries. Physiol Res 2020;69:261-74.

11 Moor D, Aggarwal G, Quiney N. Systemic response to surgery. Surgery 2017;35:220-3.

12 Marik PE, Flemmer M. The immune response to surgery and trauma: implications for treatment. J Trauma Acute Care Surg 2012;73:801-8.
13 Burton D, Nicholson G, Hall G. Endocrine and metabolic response to surgery. BJA Education 2004:4:144-7.

14 Golubovska I, Vanags I. Anaesthesia and stress response to surgery. Proc Latv Acad Sci B: Nat Exact Appl Sci 2008;62:141-7.

15 Giannoudis PV, Dinopoulos H, Chalidis B, et al. Surgical stress response. Injury 2006;37 Suppl 5:S3-9.

16 Gulielmos V, Menschikowski M, Dill H, et al. Interleukin-1, interleukin- 6 and myocardial enzyme response after coronary artery bypass grafting - a prospective randomized comparison of the conventional and three minimally invasive surgical techniques. Eur $\mathrm{J}$ Cardiothorac Surg 2000;18:594-601.

17 Meng F, Ma J, Wang W, et al. Meta-analysis of interleukin 6, 8, and 10 between off-pump and on-pump coronary artery bypass groups. Bosn J Basic Med Sci 2017;17:85-94.

18 Hahnenkamp K, Herroeder S, Hollmann MW. Regional anaesthesia, local anaesthetics and the surgical stress response. Best Pract Res Clin Anaesthesiol 2004;18:509-27.

19 Djaiani G, Fedorko L, Beattie WS. Regional anesthesia in cardiac surgery: a friend or a foe? Semin Cardiothorac Vasc Anesth 2005;9:87-104.

20 Roca J, Valero R, Gomar C. Pain locations in the postoperative period after cardiac surgery: chronology of pain and response to treatment. Rev Esp Anestesiol Reanim 2017;64:391-400.

21 Mello LCde, Rosatti SFC, Hortense P. Assessment of pain during rest and during activities in the postoperative period of cardiac surgery. Rev Lat Am Enfermagem 2014;22:136-43.

22 Li X, Feng Y, Yang B-X. Postoperative pain after cardiac surgery. $J$ Cardiothorac Vasc Anesth 2010;24:1025-6.

23 Zubrzycki M, Liebold A, Skrabal C, et al. Assessment and pathophysiology of pain in cardiac surgery. $J$ Pain Res 2018;11:1599-611.

24 Ueshima H, Kitamura A. Blocking of multiple anterior branches of intercostal nerves (Th2-6) using a transversus thoracic muscle plane block. Reg Anesth Pain Med 2015;40:388.

25 Jellish WS, Oftadeh M. Enhanced recovery after surgery for cardiac surgery: will we have the techniques needed to reduce opioid use and still provide appropriate analgesia? J Cardiothorac Vasc Anesth 2019;33:547-8

26 Fujii S, Roche M, Jones PM, et al. Transversus thoracis muscle plane block in cardiac surgery: a pilot feasibility study. Reg Anesth Pain Med 2019;44:556-60.

27 Aydin ME, Ahiskalioglu A, Ates I, et al. Efficacy of ultrasound-guided transversus thoracic muscle plane block on postoperative opioid consumption after cardiac surgery: a prospective, randomized, double-blind study. J Cardiothorac Vasc Anesth 2020;34:2996-3003.

28 Bloc S, Perot BP, Gibert H, et al. Efficacy of parasternal block to decrease intraoperative opioid use in coronary artery bypass surgery via sternotomy: a randomized controlled trial. Reg Anesth Pain Med 2021;46:671-8.

29 Chan A-W, Tetzlaff JM, Gøtzsche PC, et al. SPIRIT 2013 explanation and elaboration: guidance for protocols of clinical trials. BMJ 2013;346:e7586.

30 Xu YJ, Chen WK, Zhu Y, et al. Effect of thoracic epidural anaesthesia on serum vascular endothelial growth factor $\mathrm{C}$ and cytokines in patients undergoing anaesthesia and surgery for colon cancer. $\mathrm{Br} \mathrm{J}$ Anaesth 2014;113 Suppl 1:i49-55. 